\title{
Erratum
}

\section{Lower marine fungi (Labyrinthulomycetes) and the decay of mangrove leaf litter}

G. B. Bremer

School of Biological Sciences, University of Portsmouth, King Henry Ist Street, Portsmouth POI 2DY, United Kingdom

Hydrobiologia 295: 89-95, 1995.

Y. S. Wong \& N. F. Y. Tam (eds), Asia-Pacific Symposium on Mangrove Ecosystems.

The figures were unfortunately omitted from the above article. We now present them (with legends) in this Erratum.

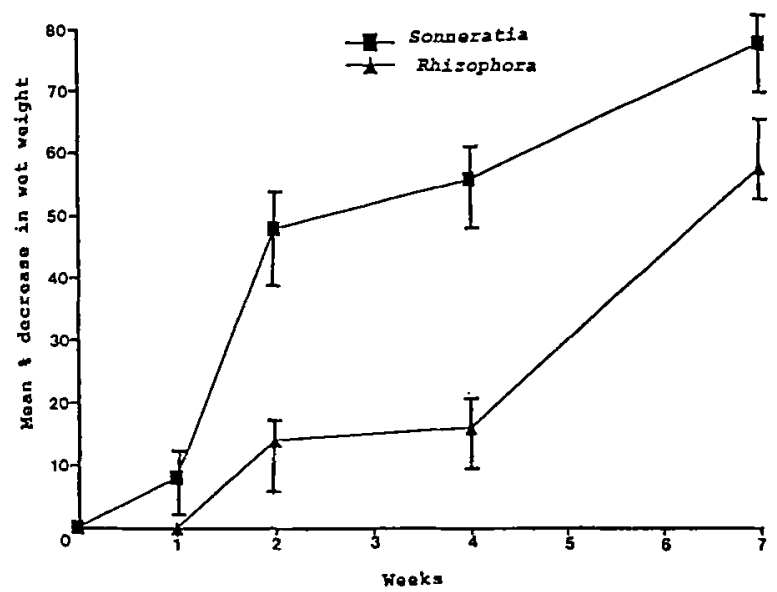

Fig. 1. The decrease in weight of leaf discs of Sonneratia and Rhizophora immersed for 7 weeks in a mangrove at Morib, Malaysia. 

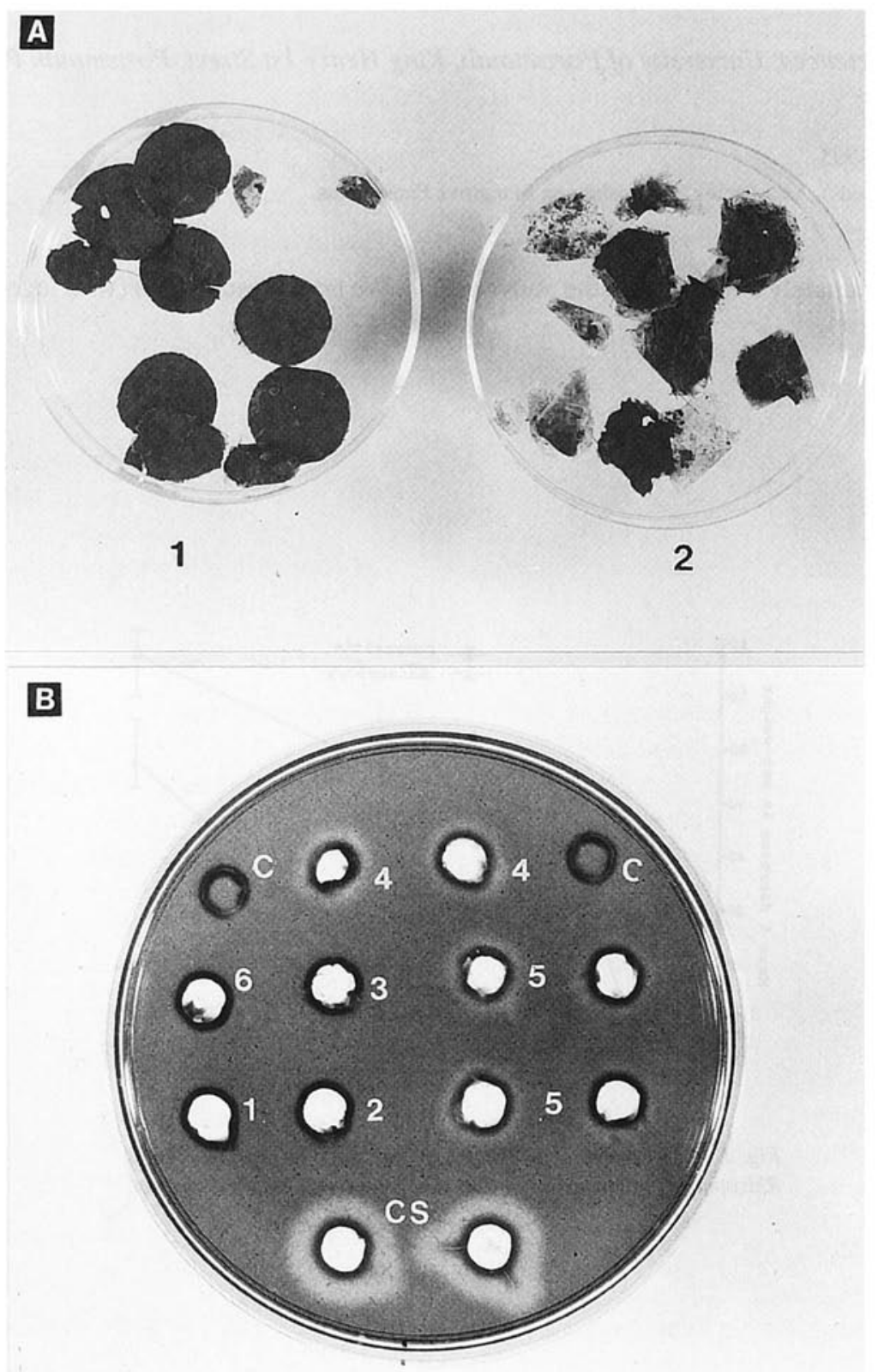

Fig. 2. (a) The appearance of Somneratia leaf discs incubated at $25^{\circ} \mathrm{C}$ for 14 days in the presence of Scizochymium aggregatum (2) contrasted with the control discs (1). (b) The results of a carboxymethylcellulose agar assay as described in the text. $1-6=$ age of culture in days, $\mathrm{C}=$ uninoculated medium as control, $\mathrm{CS}=$ cellulase standard. 

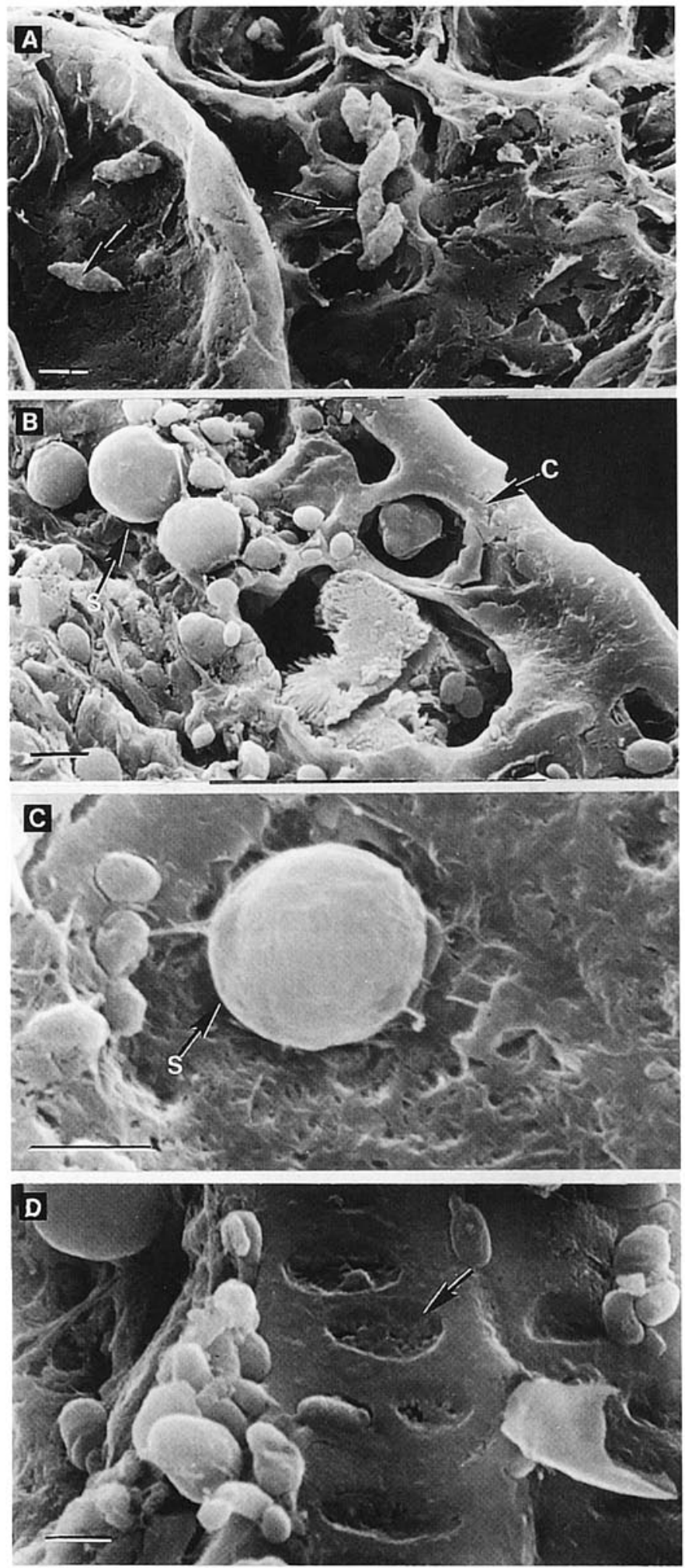

Fig. 3. Scanning electron micrographs of freeze fractures of leaves of Smmeratia inoculated with marine protists. (a) Vegetative cells of Laby whthla (arrowed) within the leaf tissue. Magnification scale bar $=40 \mu \mathrm{m}$. (b) Fracture through the epidermis showing the cuticle (C) with sporangia of the thraustochytrid (S) lying just beneath. Magnification bar $=30 \mu \mathrm{m}$. (c) Sporangium of a thraustochytrid (S) attached to the internal leaf surface with evidence of localised degradation. Magnification scale bar $=30 \mu \mathrm{m}$. (d) Eroded areas (arrowed) of the internal cell walls of the leaf. Magnification bar $=20 \mu \mathrm{m}$. 